\title{
Emansipasi Perempuan dalam Novel Hanum Karya Mustofa W. Hasyim (Kajian Feminisme)
}

\author{
Hajrin Y. Paneo \\ Salam \\ Sitti Rachmi Masie \\ Universitas Negeri Gorontalo \\ Pos-el: hajrinpaneo97@gmail.com \\ salamtolaki@ung.ac.id \\ sirachma80@gmail.com
}

DOI: $10.32884 /$ ideas.v6i4.297

\begin{abstract}
Abstrak
Penelitian ini bertujuan mendeskripsikan: (1) peran tokoh perempuan dalam novel Hanum karya Mustofa W. Hasyim; (2) bentuk manifestasi gender pada posisi kaum perempuan dalam novel Hanum karya Mustofa W. Hasyim; (3) bentuk perlawanan kaum perempuan untuk menghentikan ketidakadilan gender dalam novel Hanum karya Mustofa W. Hasyim. Teori yang digunakan sebagai pendukung dalam penelitian adalah teori feminisme Betty Friedan dan menggunakan metode deskriptif analisis untuk mendeskripsikan emansipasi perempuan dalam novel. Teknik pengumpulan data dalam penelitian ini dilakukan dengan teknik membaca dan teknik mencatat. Setelah itu, data dianalisis dengan mengidentifikasi, mengkaji, dan menyimpulkan data. Hasil penelitian dan pembahasan dalam novel Hanum karya Mustofa W. Hasyim terdapat emansipasi perempuan, yaitu mengungkapkanperantokoh perempuan, bentuk manifestasi gender pada posisi kaum perempuan yang dilakukan dengan cara melawan hegemoni dan melawan paradigma developmentalism. Selanjutnya, terdapat juga bentuk perlawanan kaum perempuan untuk menghentikan ketidakadilan gender, yaitu dimulai dari upaya jangka pendek dan upaya jangka panjang.
\end{abstract}

\section{Kata Kunci}

Feminisme, emansipasi, perempuan, novel Hanum.

\begin{abstract}
This study aimed to describe: (1) the role of female characters;(2) the form of gender manifestation in the women's position;(3) the form of women's resistance for stopping gender injustice in Hanum, a novel by Mustofa W. Hasyim. The present study employed Betty Friedan's theory of feminism to support this research. It also relied on a descriptive analysis method to describe the emancipation of women in the novel. Further, the data collection techniques were carried out by reading and note-taking strategies. Then, the data were analyzed by identifying, reviewing, and concluding the data. The results indicated that the novel showed the emancipation of women by revealing the role of female characters. The form of gender manifestation in the women's position was done by fighting hegemony and the paradigm of developmentalism. Moreover, women's resistance to stopping gender injustice was starting from short-term efforts and long-term efforts.
\end{abstract}

Keyword

Feminism, emancipation, women, Hanum. 


\section{Pendahuluan}

- Kisah tentang perempuan dari dulu sampai sekarang sangat menarik untuk diperbincangkan.Uraian tentang perempuan yang selalu diperbincangkan berupa penggambaran bentuk tubuh perempuan, segala bentuk ketidakadilan yang menimpa perempuan, perlakuan laki-laki terhadap perempuan, dan pendiskriminasian. Bukan hanya itu, uraian tentang perempuan yang sudah bisa melanjutkan pendidikan tinggi sudah bisa bekerja di luar rumah dan sudah bisa menduduki kursi kepemimpinan juga banyak digambarkan melalui novel-novel saat ini.

Pendekatan yang digunakan dalam penelitian ini adalah pendekatan strukturalisme (Nurgiantoro, 2015: hlm. 57). Pendekatan strukturalisme berfokus pada unsur-unsur intrinsik dalam novel. Sebuah sastra, fiksi (novel), atau puisi menurut pandangan kaum strukturalisme adalah sebuah totalitas yang dibangun secara koheren oleh berbagai unsur (pembangun)-nya. Struktur karya sastra merujuk pada pengertian adanya hubungan antarunsur (intrinsik) yang bersifat timbal balik, saling menentukan, saling memengaruhi, yang secara bersama membentuk satu kesatuan yang utuh (Nurgiantoro, 2015: hlm. 57).

Melihat situasi di era saat ini, novel yang lebih banyak mendapatkan penghargaan adalah novel yang mengulas tentang percintaan dan juga pendidikan. Lebih ironisnya, novelnovel percintaan yang akan merusak generasi bangsa, terutama bagi kaum perempuan. Lain halnya dengan novel Hanum karya Mustofa W. Hasyim yang memiliki keunikan sehingga peneliti tertarik untuk mengkajinya. Salah-satunya, novel ini menceritakan semangat tokohtokoh perempuan dalam membuktikan bahwa di era saat ini kaum perempuan sudah bisa memiliki hak untuk bisa berkarya.Terdapat juga tokoh-tokoh perempuan sebagai inspiratif bagi kaum perempuan. Misalnya, tokoh Hanum yang memiliki semangat dan keberanian untuk menolak adanya kebijakan-kebijakan para penguasa. Begitu juga dengan toko-tokoh lain yang memiliki semangat dalam dunia pekerjaan, politik, dan juga pendidikan. Novel Hanum menceritakan manusia-manusia muda Indonesia yang sadar bahwa berada di tengah persilangan zaman dan gempuran dari penjajahan ekonomi, mereka harus bersikap dan berani melakukan perlawanan yang cerdik dan berkualitas.

Kajian feminisme Betty Friedan digunakan untuk mengkaji kesetaraan antara kaum perempuan dan kaum laki-laki baik di bidang politik, ekonomi, dan pendidikan. Oleh karena 
itu, penelitian ini bermaksud untuk mengungkapkan adanya emansipasi kaum perempuan pada novel Hanum dengan menggunakan dua persoalan (Fakih, 2008: hlm. 152-157). Pertama, manifestasi gender pada posisi kaum perempuan yang meliputi hubungan ekonomi, politik, kultural, ideologi, lingkungan, dan termasuk di dalamnya hubungan antara laki-laki dan perempuan. Dengan adanya hubungan tersebut, emansipasi perempuan, yaitu pembebasan perbudakan, dilakukan dengan melawan hegemoni dan melawan paradigma teori pembangunan (developmentalisme). Kedua, ketidakadilan gender harus dihentikan dengan menggunakan upaya yang bersifat jangka pendek dan upaya yang bersifat jangka panjang.

\section{Metode}

Metode yang digunakan dalam penelitian ini adalah pendekatan kualitatif dan jenis penelitian deskriptif analisis. Data dalam penelitian ini berupa data lunak yang berwujud kutipan-kutipan emansipasi perempuan dalam novel Hanum karya Mustofa W. Hasyim. Sumber data dalam penelitian ini adalah Novel Hanum karya Mustofa W. Hasyimtahun 2009, penerbit Republika, setebal 213 halaman. Teknik pengumpulan data dilakukan dengan teknik membaca dan mencatat hal yang penting untuk dicatat terkait dengan penelitian ini. Sementara itu, untuk teknik analisis data dilakukan dengan mengidentifikasi data yang termasuk emansipasi perempuan dalam novel Hanum karya Mustofa W. Hasyim, pada tahap ini peneliti terlebih dahulu membaca berulang-ulang, kemudian memilah data dengan mendeskripsikan apa yang dilihat pada saat membaca. Pada tahap ini, peneliti baru mendata sepintas tentang informasi yang diperoleh. Mengkaji data berdasarkan emansipasi perempuan dengan teori yang digunakan. Pada tahap ini, peneliti mulai menggambarkan peran tokoh perempuan melalui kutipan-kutipan pada novel, kemudian mencari bentuk menifestasi gender pada posisi kaum perempuan dalam novel, dan mencari bentuk perlawanan kaum perempuan untuk menghentikan ketidakadilan gender dalam novel Hanum karya Mustofa W. Hasyim dengan melakukan analisis mendalam. Langkah selanjutnya adalah menyimpulkan data, yaitu memaparkan emansipasi perempuan secara jelas dan terperinci, kemudian menyimpulkan emansipasi perempuan, yaitu peran tokoh perempuan, bentuk menifestasi gender pada posisi perempuan, bentuk perlawanan kaum perempuan untuk menghentikan ketidakadilan gender dalam novel Hanum karya Mustofa W. Hasyim.

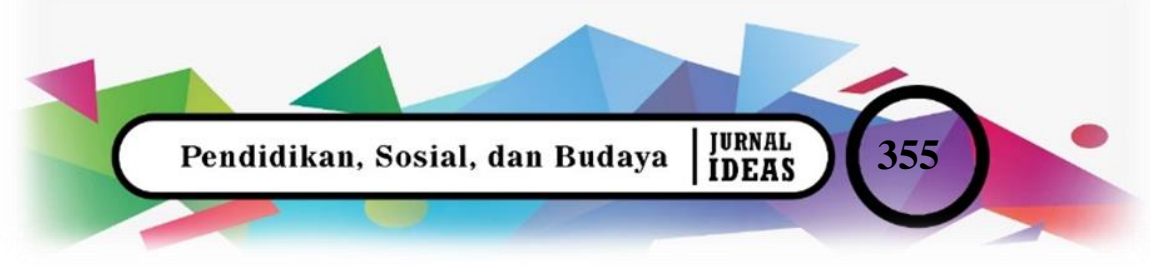




\section{Hasil dan Pembahasan}

\section{Hasil}

Hasil penelitian ini akan diuraikan dengan memfokuskan tiga permasalahan, yaitu sebagai berikut.

1. Peran tokoh perempuan dalam novel Hanum karya Mustofa W. Hasyim.

2. Bentuk manifestasi gender pada posisi kaum perempuan pada novel Hanum karya Mustofa W. Hasyim.

3. Bentuk perlawanan kaum perempuan untuk menghentikan ketidakadilan gender pada novel Hanum karyaMustofa W. Hasyim.

\section{Peran Tokoh Perempuan dalam Novel Hanum Karya Mustofa W. Hasyim}

Adapun beberapa tokoh perempuan yang menjadi pelopor emansipasi perempuan dalam novel Hanum Karya Mustofa W. Hasyim terdiri dari Hanum, Maya, Linda, Sarah, Asri, Nenek Hanum, Sur (Ibu Hanum), Mbak Lela dan Nenek Tua. Hal ini dapat dijelaskan sebagai berikut.

\section{Tokoh Utama}

a. Hanum

Hanum adalah seorang gadis kecil yang ceria. Setelah dewasa, Hanum menjadi pelopor perempuan yang telah melahirkan emansipasi lewat keberaniannya memimpin demonstrasi bersama para pedagang kecil.

"Saya sejak pagi menguping pembicaraan antarpetugas keamanan ini.Ternyata, hari ini Hanum menggerakan demonstrasi. Para pegadang kecil dipasar tradisional sekabupaten iakumpulkan.Menurutrencana,demonstrasi besarbesaran para pedagang itu akan bergerak menuju ke kantor dewan tingkat provinsi" (Hanum, 2009: hlm. 148).

Peran Hanum berpengaruh besar dalam sebuah emansipasi, keberanian Hanum melakukan perlawanan merupakan wujud pembebasan bahwa saat ini kaum perempuan sudah bisa melakukan apa yang dilakukan oleh kaum laki-laki. Tidak banyak kaum perempuan yang berani untuk mempimpin sebuah demonstrasi terutama untuk melawan pemerintah. Lain hal dengan Hanum yang begitu gigih dan berani. Perlawanan yang dipimpin Hanum dibantu para pedagang kecil di pasar tradisional. 
b. Maya

Maya merupakan teman Hanum yang membantu perempuan hamil untuk berjualan. Peran Maya dalam novel ini menjelaskan bahwa dengan bekerja akan mendapatkan pengalaman (untuk menjadi pedagang). Pengalaman tersebut didapat dari Mbak Lela,yaitu perempuan hamil. Mbak Lela menjelaskan semua hal tentang berjualan, seperti dalam hal tawar-menawar. Ketika bekerja menjadi pedagang kaki lima, harga barang harus ditawarkan setinggi mungkin agar pembeli ketika menawar harga rendah, tetap akan mendapatkan keuntungan. Itulah penjelasan dari perempuan hamil tersebut.

"Maya mendapatkan banyak pengalaman.Setiap hari mendapat pengalaman baru. Kadang, ia takut juga menawarkan harga dagangan empat kali lipat dari pembelian, tetapi setelah Mbak Lela, perempuan hamil itu, memberitahu bahwa di kaki lima seperti ini harga barang harus ditawarkan setinggi mungkin sebab para pembeli hampir dipastikan akan menawar lebih rendah. Paling tidak separo. Kalau barang ditahan sebentar, tawaran pembeli akan naik sedikit demi sedikit. Saat dilepas, pasti sudah untung" (Hanum, 2009:78).

Dengan bekerja, Maya juga mengetahui kapan pasokan barang datang, dari mana saja, siapa pemasoknya, dan bahkan harga asli barang-barang pun Maya ketahui. Maya bisa menghitung beberapa keuntungan pedagang di tempat dia bekerja. Terlihat jelas bahwa perempuan sangat berpengaruh dalam hal perekonomian.

2. Tokoh Tambahan

a. Linda

Kegigihan Linda untuk menafkahi keluarganya merupakan salah satu bentuk bahwa peran perempuan saat ini sudah sangat dibutuhkan apalagi di saat perekonomian keluarga tidak cukup.

"Sukma ketemu Linda yang mau mencoba pakaian baru."

"Lho, Mbak Linda?"

"Mas Sukma?"

"Ya, saya harus berhemat, Mas. Saya harus ingat kebutuhan sekolah adik saya".

"Saya kan harus menabung untuk hari tua. Kalau dompet saya terkuras oleh mode terbaru dengan merek asli, maka tabungan kosong. Kalau pada saatnya nanti harus harus menikah kan repot sendiri" (Hanum, 2009: hlm. 68).

Linda merupakan perempuan yang sederhana dan rajin untuk membantu perekonomian keluarga dia bekerja di mal. Untuk menghemat biaya Linda lebih

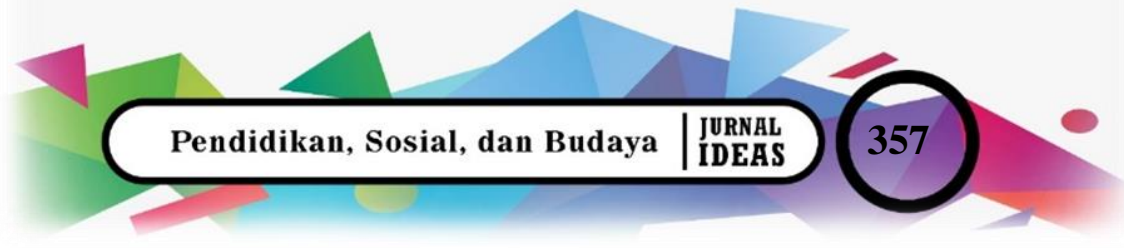


memilih berbelanja pakaian yang lebih murah karena mengingat kebutuhan sekolah untuk adiknya dan menyisipkan uangnya ditabungan untuk hari tuannya.

b. Sarah

Pekerjaan di luar rumah yang dilakukan oleh kaum perempuan terkadang membuat seseorang untuk berhati-hati. Sarah merupakan salah satu perempuan yang berkerja di mal.

"Obrolan asyik dimulai. Dengan cerdik Sarah mulai mengarahkan pada pengalaman dua gadis berseragam yang bekerja di kantor pemasaran mall. Siang itu pas saatnya makan siang.Mereka mau saja diajak Sarah yang dikenal suka berseliweran di mall dan akrab dengan semua pegawai, termasuk satpam dan tukang parkir di bawah. Sarah dikenal sebagai gadis mall" (Hanum, 2009: hlm. 102).

Kutipan di atas menjelaskan bahwa Sarah di kenal sebagai gadis mall. Semua pegawai mengenal Sarah, bahkan termasuk satpam dan tukang parkir yang berjagajaga di bawah.Bekerja di mall merupakan bentuk pembebasan bahwa perempuan sudah bisa bekerja di luar rumah.

c. Astri

Pendidikan tinggi saat ini sudah banyak diminati oleh kaum perempuan. Astri termasuk perempuan muda yang melanjutkan pendidikan..

"Perempuan-perempuan muda itu terus berseliweran. Satu dua sempat melirik. Sukma berdebar ketika ada mahasiswi mirip Ashley Olsen tersenyum. Terasa Sukma terbang ke New York, berpetualangan di sana, Sukma membalas senyum itu.

Gila. Perempuan semampai itu mendekat. Teman Sukma bersiul lirih.

"Nggak kuliah nih," sapa perempuan itu.

"Nanti siang. Habis dosennya masih mengajar di kampus lain," jawab Sukma berbohong (Hanum, 2009: hlm. 39).

Astri merupakan mahasiswi muda yang mirip dengan Ashley Oslen. Astri juga merupakan tokoh perempuan yang memiliki peran dalam pendidikan.Dia melanjutkan pendidikan tinggi dan juga merupakan model cantik.

\section{d. Nenek Hanum}

Nenek Hanum merupakan perempuan tua yang masih telaten dalam mengolah gadung untuk mengeluarkan racun. Ketelatenan Nenek Hanum merupakan salah satu bentuk bahwa perempuan di masa dulu diberikan kesempatan untuk mengolah dan mempelajari hasil perkebunan. 
"Biar Nenek saja yang masih telaten mengolah umbi gadung menjadi siap makan. Untuk mengeluarkan racun dari gadung diperlukan banyak proses, memakan waktu dan tenaga,meski kalau sudah jadi gadunggoreng yang keripik dan gurih jelas menjadi rebutan orang" (Hanum, 2009: hlm. 17).

Dilihat dari kutipan di atas menjelaskan bahwa perempuan tua pun masih memiliki keahlian dalam mengolah ubi gadung. Proses untuk mengolah ubi tersebut membutuhkan proses, waktu, dan bahkan tenaga. Keahlian yang dimikili oleh Nenek Hanum pekerjaan rumah tangga yang dipelajari pada masa muda. Di masa tersebut kaum perempuan lebih banyak diajar pekerjaan rumah tangga.

e. Sur (Ibu Hanum)

Peran tokoh Sur (Ibu Hanum) merupakan ibu rumah tangga yang memiliki satu anak, yaitu Hanum. Sur termasuk ibu yang tidak pernah melarang dan mengekang Hanum untuk melakukan berbagai hal termasuk melanjutkan pendidikan dan bahkan dia mendukung semua kegiatan anaknya selagi itu positif.

"Sing penting slamet, Bu," bisik pengacara senior ke dekat telinga Ibu Hanum.

"Dan kita dapat melawan ketidakadilan dalam pengadilan ini dengan cara membuat senyap gedung ini," jawan Ibu Hanum (Hanum, 2009: hlm. 194).

Kutipan di atas menandakan bahwa Sur merupakan ibu yang mendukung semua apa yang dilakukan oleh anaknya selagi itu merupakan hal yangpositif. Ketika Hanum dipenjara dan diadili dalam pengadilan, Ibu Hanumlah yang selalu memberikan penguatan kepada Hanum. Masa kecil Hanum, Sur sudah membantu perekonomian keluarga dengan cara berdagang di pasar.

f. Mbak Lela

Bukan hanya tokoh Hanum yang membuktikan adanya emansipasi, ada juga beberapa tokoh perempuan lainnya.

"Seorang perempuan, tidak begitu muda, hamil tua, mendorong gerobak berupa kotak besi beroda bersama suami.Keluar dari jalan sempit menuju jalan besar. Sampai di depan deretan toko mereka berhenti. Kotak besi dibuka. Besi-besi penopang dikeluarkan lebih dahulu.Dipasang sekrupnya, ditata. Barang dagangan berupa pakaian yang sudah terpasang di hanger dikeluarkan. Perempuan itu tampak letih.Matahari mulai terasa panasnya. Ia mengambil barang sekuatnya, lalu ia tata. Suami sibuk membongkar barang"(Hanum,2009: 75).

Kutipan di atas menjelaskan bahwa seorang perempuan hamil pun sudah bisa bekerja di luar rumah. Dari kutipan-kutipan sebelumnya menjelaskan tentang peran 
Hanum pada dunia perpolitikan, berbeda hal dengan kutipan ini menjelaskan seorang perempuan hamil terjun langsung ke dunia perekonomian untuk membantu suaminya menjual barang dagangan berupa pakaian dan sebagainya. Terlihat bahwa perempuan hamil tersebut tampak letih, dia tetap membantu suaminya.Inilah penjelasan bahwa peran perempuan sudah meluas dilihat dari bidang ekonomi dan juga politik.

g. Nenek Tua

Partisipasi tokoh perempuan guna melakukan pembebasan dari anggapan bahwa kaum perempuan tidak mampu bekerja di luar rumah sudah terealisasi.Dapat dilihat bahwa untuk menyambung hidup, seorang nenek tua pun masih berkerja.

"Hanum maju memeluk nenek tua yang masih terus berjualan untuk menyambung hidup itu erat-erat" (Hanum, 2009: hlm. 205).

Melihat situasi saat ini, bukan hal yang biasa lagi bagi perempuan yang bekerja di luar rumah. Pergantian masa membuat banyak perubahan, terutama bagi kaum perempuan.Perempuan yang dahulunya hanya bekerja di dalam rumah (ranah domestik), sekarang sudah bisa bekerja di luar rumah guna menyambung hidup.

Peran perempuan dalam novel Hanum menjelaskan bahwa pentingnya peran kaum perempuan untuk terjun ke bidang ekonomi dan politik. Dengan adanya peran tersebut mempermudah kaum laki-laki untuk melakukan berbagai hal, misalnya melakukan pekerjaan di luar rumah.

Saat ini, pendidikanlah sangat penting bagi kaum perempuan agar dapat belajar tentang arti pembebasan yang sesungguhnya. Dengan adanya pendidikan, kaum perempuan bisa membedakan mana yang baik dilakukan dan mana yang buruk untuk tidak dilakukan.

\section{Bentuk Manifestasi Gender pada Posisi Kaum Perempuan dalam Novel Hanum Karya Mustofa W. Hasyim}

1. Melawan Hegemoni

Di era saat ini, kaum perempuan telah mampu membangkitkan kesadaran masyarakat bahwa untuk melawan hegemoni harus dilakukan dengan melalui pendidikan. Hal tersebut agar mendapatkan gagasan dan nilai yang baru untuk membantu kaum perempuan memahami pengalamannya, menolak ideologi dan norma yang dipaksakan kepada kaum perempuan. Novel Hanum mengisahkan perempuan-perempuan muda bahwa pendidikan itu sangat penting bagi kaum perempuan. 
Dengan adanya pendidikan, kaum perempuan bisa belajar dan menambah ilmu pengetahuan mereka, seperti pada kutipan dibawah ini.

"Hanum termasuk anak pandai di sekolah.Selalu naik kelas, selalu juara.Ia paling pandaiberhitung, pandai Matematika, juga bahasa, juga ilmu alam, tumbuhtumbuhan, dan sejarah. Jadi, kepandaiannya komplet. Kalau mendapat tugas mengarang, ia selalu selesai nomor satu dan nilainya terbaik. Gurunya sering heran.Anak ini memang istimewa. Kalau mengarang, bahasanya hidup.yang ditulis selalu hal yang menarik dan baru. Pengalaman yang ia serap demikian banyak. Seolah tahu semua isi pelosok dunia." (Hanum, 2009: hlm. 26-27)

Kutipan di atas menjelaskan bahwa kecerdasan dan kepandaian yang dimiliki oleh Hanum merupakan gambaran bahwa perempuan juga mampu dalam hal berpikir, dan pendidikan juga memberikan banyak pengalaman.Di era modernisasi ini, pendidikanlah yang paling utama untuk membentuk karakter agar jauh lebih baik. Bukan hanya kaum laki-laki yang bisa melanjutkan pendidikan, kaum perempuan pun juga bisa. Melihat situasi saat ini, persaingan dalam bidang pendidikan makin banyak. Bukan hanya kaum laki-laki, kaum perempuan pun terus bersaing untuk melanjutkan pendidikan lebih tinggi lagi. Inilah bukti bahwa dengan melawan hegemonibisa mengantarkan kaum perempuan pada kedudukan yang tinggi dan memiliki martabat yang baik.

2. Melawan Paradigma Teori Pembangunan (Developmentalism)

Asumsi adanya keterbelakangan perempuan menyebabkankaumperempuan tidak dapat berpartisipasi dalam pembangunan. Anggapan bahwa perempuan tidak bisa memecahkan masalahny asendiri perlu adanya pertukaran ide atau gagasan secara organisasi untuk memahami kaum perempuan dengan pengetahuan, pemikiran, atau pengalaman secara nyata, seperti halnya pada kutipan dibawah ini.

“Untuk apa ia mengumpulkan para pedangang itu?"tanya Sukma pada pertemuan tiga orang di asrama Maya.

"Katanya untuk menyusun kekuatan."

"Menyusun kekuatan? Untuk apa?"tanya Thalib.

"Untuk melakukan perlawanan. Kalau perlu, perlawanan maksimum."

"Wah, dia telah bertindak sendiri. Tidak menunggu kita menyusun strategi."

"Hanum sudah tidak sabar lagi.Malah dia menuduh kita terlalu lamban."

"Bagi dia, perlawanan harus segera dimulai?"

"Ya, menurut dia, perlawanan telah dimulai."

"Ini betul-betul di luar dugaan kita.Di luar kendali kita."

“Dia memilih berjalan sendiri”(Hanum, 2009:132).

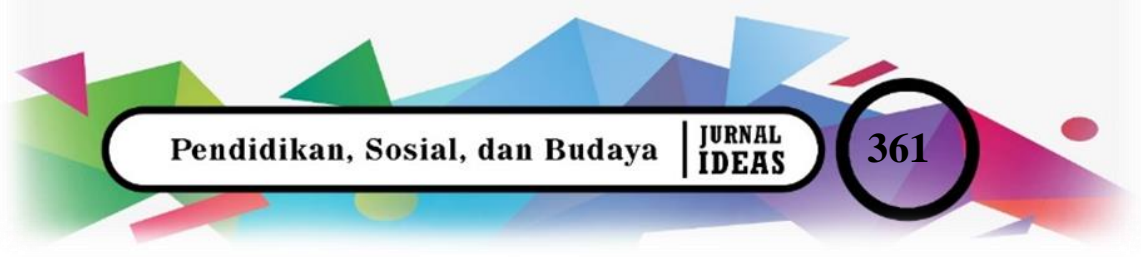


Kutipan di atas menjelaskan bahwa Thalib dan juga Sukma melibatkan Maya terkait permasalahan yang terjadi pada Hanum. Mereka membahas Hanum yang telah lebih dulu mengambil tindakan untuk melakukan perlawanan kepada pemerintah. Maya menjadi sumber informasi adanya masalah Hanum yang ingin bertindak mengungkapkan masalah pembunuhan berencana. Maya menginformasikan kepada Sukma dan Thalib bahwa Hanum telah mengambil kesimpulan dengan terbunuhnya kakek dan nenek Hanum berkaitan dengan pencaplokan pasar, dan pembunuhan tersebut telah direkayasa oleh pemerintah.

\section{Bentuk Perlawanan Kaum Perempuan untuk Menghentikan Ketidakadilan Gender dalam Novel Hanum Karya Mustofa W. Hasyim}

1. Upaya Jangka Pendek

Adapun upaya jangka pendek untuk menghentikan masalah kekerasan, pelecahan,dan berbagai stereotip terhadap kaum perempuan perlu diupayakan.Kaum perempuan sendiri mulai memberikan pesan penolakan secara tegas kepada mereka yang ingin melakukan kekerasan pelecehan, seperti pada kutipan di bawah ini.

"Suami Mbak Lela, setelah Mbak Lela melahirkan dan sibuk dengan bayinya di rumah, dia mulai genit dan berani menggoda saya."

"Wah, gawat."

"Lebih gawat lagi kalau kau malah menikmati godaan dia."

Maya menggeleng."Tidak. Saya justru muak dengan cara dia menggoda dan merayu saya. Dia obral rayuan, obral lirikan mata, obral kata-kata gombal. Ketika mau mencoba mengobral tangan di sela-sela barang dagangan saya tepis dan saya menunjukkan kalau saya marah."

"Itu bagus. Bagaimana rekasi dia?"

"Terkejut. Lalu minta maaf dan menyatakan penyelsalannya. Meski begitu saya mulai merasa terancam" (Hanum, 2009: hlm. 85-86).

Kutipan di atas menjelaskan bahwa Maya sedang menolak perbuatan suami Mbak Lela yang ingin melecehkannya. Tindakan penolakan yang dilakukanMaya merupakan upaya untuk menghentikan pelecehan yang dirasakan oleh kaum perempuan. Cara Maya menepis dan menunjukkan ekspresi marah merupakan upaya jangka pendek untuk menghentikan kekerasan dan pelecehan. Ketegasan Maya untuk melakukan penolakan membuat suami Mbak Lelah meminta maaf kepadanya. 
2. Upaya Jangka Panjang

Usaha perjuangan jangka panjang merupakan salah satu bentuk untuk memperkuat upaya praktis, yaitu upaya jangka pendek. Ketika upaya praktis gagal karena hambatan ideologis, misalnya bias gender yang mengarah pada masyarakat untuk menyalahkan korbannya, perjuangan kaum perempuan dilakukan dengan melancarkan kampanye berupa kesadaran kritis dan pendidikan umum masyarakat untuk menghentikan berbagai bentuk ketidakadilan gender yang dirasakan oleh kaum perempuan.

"Ini merupakan perjuangan jangka panjnag sebab lawan yang kuhadapi ramairamai juga memiliki napas panjang untuk menghadapi perlawanan seperti ini. Jadi,apa salahnya berhemat energi, tidak semua terlibat langsung, tidak semua menanggung risiko dari sebuah aksi. Yang lain perlu sembunyi, tiarap, untuk memerhatikan cuaca. Dengan demikian, strategi perjuangan senantiasa dapat diperbaharui, taktik dapat dipersegar, dan siasat serta teknik pergerakan dapat dicari alternatifnya"

(Hanum, 2009: hlm. 171).

Perjuangan jangka panjang yang dirasakan oleh Hanum merupakan perjuangan yang tidak mudah.Dirinya sebagai perempuan hanya bisa memperbaharui diri dan menunggu untuk dibebaskan. Ketika upaya jangka pendek berhenti dan tidak berdaya karena hambatan ideologis yang disebabkan olehbias gender, maka diadakan upaya jangka panjang berupa pembentukan sebuah organisasi untuk melakukan kampanye tentang kesadaran kritis dan pendidikan umum masyarakat untuk menghentikan berbagai bentuk ketidakadilan gender.

\section{Simpulan}

Berdasarkan uraian hasil penelitian dan pembahasan, simpulan dalam penelitian ini adalah hal-hal yang dilakukan terhadap emansipasi perempuan, yaitu manifestasi gender pada posisi kaum perempuan dilakukan dengan dua cara: (1) melawan hegemoni yang merendahkan kaum perempuan, kemudian (2) melawan paradigmadevelopmentalismyang beranggapan bahwa keterbelakangan kaum perempuan disebabkan karena kaum perempuan tidak berpartisipasi dalam pembangunan. Selanjutnya, menghentikan ketidakadilan gender dan memperjuangkan keadilan gender. Untuk menghentikan ketidakadilan gender dapat dilakukan dengan beberapa upaya, yaitu: 1) upaya jangka pendek yang dapat memecahkan masalah-masalah praktis tentang ketidakadilan gender, dan; 2) upaya jangka panjang untuk memperkuat usaha dan upaya jangka pendek. 


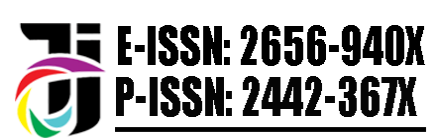

URL: jurnal.ideaspublishing.co.id
Volume: 6

Nomor: 4

Bulan: November

Tahun: 2020

\section{Daftar Rujukan}

Fakih, M. (2008).Analisis Gender dan Transformasi Sosial. Yogyakarta: Pustaka Pelajar.

Friedan, B (2001). The Feminine Mystique. NewYork: Library of Congress Cataloging-inPublication Data.

Hasyim, M. W. (2009). Hanum. Jakarta: Penerbit Republika.

Murniati, N. A. (2004). Getar Gender Perempuan Indonesia dalam Perspektif Sosial, Politik, Ekonomi, Hukum dan HAM. Malang: Perpustakaan Nasioanl RI (KDT).

Ritonga, D. S. (2016). “Kajian Gender pada Novel Karya Nawal El Saadawi dan Sutan Takdir Alisjahbana". 